\title{
10
}

\section{AGENDA 21 FOR THE BALTIC SEA REGION AND INDUSTRY}

\author{
Svante Bodin \\ Chairman of the Senior Officials Group \\ Ministry of Environment
}

Sweden

We are at a tuming point in the history of environment protection, a point at which we have achieved considerable progress in many countries making it conceivable to speak about the eradication of environmental problems caused by industry within a period of let say 10 years. This is not unrealistic in countries like Sweden, Denmark, Norway and Finland if you speak about traditional environmental load on the environment in terms of emissions to air and discharges to water. In Sweden we set that goal in 1991 for the year 2000 - but it will take a little longer. However, if you speak about achieving sustainable development then the situation is different. Then also the progressive countries in terms of environmental policies have a long way to go. Then industry would need to enter into a new stage of development.

But let us take one step back and look at the development over the last decade or so.

During the past decade environmental matters in the industrial and municipal sectors have improved considerably, industry not only addressing emissions and end-of-pipe-solutions, but also effective management of resources and of information on environmental performance, particularly in OECD countries. One of the important driving forces, still, is legislation, but the role and the impact of the market has increased rapidly during the last years. With growing environmental awareness and knowledge within the industrial sector and the business sector as a whole, as well as of the market, environmental problems and obstacles today tend to turn into possibilities. Development of technology, enhanced export opportunities with increasing market shares and effective resource management are now strategic elements for many successful companies.

Sustainable development has been established as an over all goal including ecological as well as economic and social development, deriving from the Agenda 21 and the Rio Declaration at UNCED in 1992. The Amsterdam Treaty, which 
has recently been signed by the members of the European Union, has explicitly included sustainable development as an over all goal for the European Union. However, sustainable development implies that growth and industrial development are as important as before for a wealthy and healthy society. The challenge is to keep them within a sustainable framework and limits.

To achieve a development towards sustainability we have to address all issues concerning the impact on the environment and society of industrial activities. These issues comprise in addition to reducing pollution the use of natural resources, renewable and non-renewable, and the use and eventual disposal of the products after their being circulated, including waste management. Also the properties of the products during their use would have to enter the environmental equation. It is necessary for companies to address all of these problems in developing their policies and actions to adjust to sustainable development.

In order to reach sustainable development we must broaden our perspectives on the modalities for action and the instruments to be used. Legislation and regulation are not the only ways forward. In fact, in many circumstances, cooperation between the public and private sectors are of greater importance. Voluntary actions taken by industry and constructive dialogues at different levels of society are other useful tools that need be further explored and promoted.

This seminar deals with waste management and the environment. That is one aspect of eco-efficiency in a society based on eco-cycles. The concept of ecoeffeciency is used within industry to set up a new framework facilitating the transition to sustainable development.

Eco-efficiency works at company level. The World Business Council for Sustainable Development (WBSCD) has stated that an eco-efficient company must:

1. minimise the material intensity of goods and services;

2. minimise the energy intensity of goods and services;

3. minimise toxic dispersion;

4. enhance material recyclability

5. maximise sustainable use of renewable resources

6. extend product durability;

7. increase the service intensity of goods and services

In many cases eco-efficiency will generate a win-win-situation where both environmental and financial resources are saved.

Environment management systems like EMAS and ISO14000 are two volontary systems addressing eco-efficiency, for which we have great expectations. Ecolabelling is another instrument facilitating the choice by customers between products.They have been accepted by business and customers want to see them applied to ensure good environmental performance. There is definitely a strong "market pull". The application of EMAS and ISO14000 will soon become an unavoidable requirement for those companies that want to be succesful on competitive markets. Also in this case the market will be the main driving force. 
Caring for the environment is apparently becoming a primary concern for business. For many companies, having a positive and responsible attitude towards the environment, this is a key component of their corporate image. Many companies are also moving beyond the concerns about their image to the incorporation of environment management in their business strategy. Respected environmentalists are being placed on corporate boards and many companies are setting up units specifically responsible for environmental management. Additionally companies are engaging their R\&D divisions to take into account environmental considerations in manufacturing processes as well as in product design. Life cycle analysis is providing an appropriate basis for this. These are all very positive signs.

We have already got some experience with environmental management instruments in Sweden. In Sweden 70 companies have obtained EMAS certification. That places Sweden on the third place in the European league, Germany in the lead with 850 EMAS certifications and Austria second with 80 EMAS certifications. All together 114 companies in Sweden have either EMAS or ISO14000 certification or both. We can also see the trend of smaller enterprises coming along, often as subcontractors being required by the main manufacturer to obtain certification. The ball has quite clearly started rolling.

But is it enough and what is the ultimate goal we are heading for?

In order to obtain an answer to that question we would have to look at a specific piece of work that started one year and a half ago. The answer is linked to the Agenda 21 for the Baltic Sea Region.

The Agenda 21 for the Baltic Sea Region, for short Baltic 21, signals a new era in regional cooperation. It implies a broadening of environmental cooperation and integration of responsibility for sustainable development into all sectors of society. If succesful, it will establish the environmental foundation for long term regional economic development making it ecologically sustainable.

But the cooperation in the field of environment in the Baltic Sea region has a long history.

Allow me briefly to take one step back in time and draw your attention to the origin of the "JCP" and the Summit in 1990 in Ronneby. At that meeting the heads of government decided to elaborate a comprehensive programme to restore the ecological balance of the Baltic Sea. In 1992 the Baltic Sea countries and other participants adopted the Baltic Sea Joint Comprehensive Environmental Action Programme or the JCP. Since then the JCP has been actively implemented in the region. A novel, and very productive feature, of the JCP was, and is, the strong involvement of the International Financing Institutions in the work from the very start. The IFI:s participated in Ronneby and the elaboration of the JCP. The joint priorites of the countries and the banks within the JCP has facilitated investments and simplified the procedures involved in financing. Another novel feature was the involvement of the NGO:s as partners in the JCP. As a matter of a fact NGO:s have later been established as lead parties to some elements of the JCP. 
132 so called hot spots were identified for specific remedial actions in an investment programme segment of the JCP. Only at a minor part of these no activities have been inititiated. The others are either completed or are the subject of different investment activities.

To coordinate and monitor the JCP a special body- the Programme Implementation Task Force, PITF- was established within the framework of HELCOM, the Helsinki Commission, set up to implement the Helsinki Convention for the protection of the marine environment of the Baltic Sea signed in 1974. The work has been organised by means of lead parties for different programme elements. There is a strong connection between the PITF and the original committees of HELCOM, the Technological Committee, the Maritime Committee, the Environment Committee and the Combatting Committee. These Committees are working with the elaboration of HELCOM recommendations to protect the marine environment, monitoring issues, shipping and combatting releases of hazardous substances into the sea including oil. Actions against land based sources, however,is the most comprehensive task of HELCOM.

The experiences of the JCP and HELCOM are of great value now when we are turning our efforts towards sustainable development of the Baltic Sea Region.

The modes of work developed within the JCP can be employed in the wider context of a regional Agenda 21. In fact an up-dating and strengthening of the JCP constitutes an important part of the Agenda 21 for the Baltic Sea Region.

The goal of sustainable development is firmly established by the Prime ministers of the countries of the Baltic Sea Region.

In Visby, in May 1996, the Heads of Government of the Baltic Sea Region expressed that

\section{The essential objective of the Baltic Sea cooperation is the constant} improvement of the living and working conditions of their peoples within the framewok of sustainable development, sustainable management of natural resources and protection of the environment.

At the request of the heads of government the Council of the Baltic Sea States (CBSS) in Kalmar in July 1996 adopted three action programmes. In these action programmes the transport and fishery sectors were explicitely requested to develop plans and programmes for sustainable development in addition to the general request to develop an Agenda 21 for the Baltic Sea region.

At their informal meeting at Saltsjöbaden in October 1996 the Ministers of Environment of the Baltic Sea Region adopted a declaration in which a decision was taken to start the development of an Agenda 21 for the Baltic Sea Region. The Baltic Sea Region in this context also comprises Norway and Iceland, who also participated in the ministerial meeting, in addition to the riparian states of the Baltic Sea. 
The objective of Baltic 21 is sustainable development. The Baltic 21 should lay the ecological foundation for economic development in the region making this development sustainable. A very important aspect of this work is that regional cooperation should be based on sector integration, that is that the sectors of society themselves take on responsibility for sustainable development of the sectors. Seven sectors were identified as the most important ones for sustainable development of the region; the

transport, energy, agriculture, industry, forestry, tourism and fishery sectors.

These sectors themselves should developed the necessary prerequisites for sustainable development.

The Agenda 21 for the Baltic Sea Region shall be ready for adoption at the highest political level possible in the first half of 1998.

A senior officials group (SOG) has been established to monitor and steer the development process and negotiate the final Agenda 21 document. Members of the SOG are, in addition to the countries, intergovernmental and non-govemmental organisations and the international financing institutions. I have the pleasure of chairing this group of Senior Officials.

The SOG has established lead party responsibilities for the seven sectors.

For the industry sector Sweden and the Russian Federation act jointly as lead parties. Sweden is also responsible for the agricultural sector. Germany and latvia are responsible for the transport sector, Finland and Lithuania for the forestry sector and Denmark and Estonia for the energy sector. Finland together with the Baltic Tourism Council is reponsible for the tourism sector and finally the Baltic Sea International Fishery Commission for the fishery sector.

Each of the sectors will contribute basic elements to the consolidated Agenda 21 document. These include goals and criteria for sustainable development, identification of gaps and obstacles for sustainable development, a scenario for the sector indicating a path to sustainable development and the associated policy changes implied and elements of the action programme with targets, time frames, actors and financing.

The development process will be open, transparent and democratic. In order to contribute to achieving this aim all information is made available via our Internet home page, http://www.ee/baltic21/.

On this home page you can find a working definition of sustainable development in the Baltic Sea Region as elaborated by the SOG. It reads:

\section{Sustainable Development of the Baltic Sea Region.}

"The essential objective of Baltic Sea Region co-operation is the constant improvement of the living and working conditions of their peoples within the framework of sustainable development, sustainable development o natural resources, and protection of the environment." 
Sustainable development includes three mutually interdependent dimensions economic, social and environmental.

This means for the region:

- a safe and healthy life for current and future generations

- a co-operative and prosperous economy, including satisfying social needs

- that regional co-operation is based on democracy, openness and participation

- that biological and ecosystem diversity and productivity are maintained, and pollution reduced accordingly

- increased efficiency in the use and management of renewable resources, within their regeneration capacity

- that materials flow of non-renewable resources are made efficient and cyclic, and renewable substitutes created.

The Baltic Sea Region recognises its interdependence with other parts of the world and makes its contribution to the fulfilment of sustainable development goals at the global and European level.

Allow me to retum to the industrial sector in particular for a while. The industrial sector has held two workshops so far to develop goals, indicators ,scenarios and elements in the action plan. The report from the last meeting in Moscow 17-18 September 1997 highlights the importance of eco-efficiency and the carrying capacity of natural ecosystems as goals for sustainable development within the industry sector. As indicators of eco-efficiency the use of EMAS ( Eco management and audit scheme) and ISO14001 were pointed out. The next step will be to develop a sustainable development scenario which indicates a plausible route to sustainability. But most important that secenario should also display the policy changes required to reach sustainable development. That should then be cast into an action programme. This task was actually dealt with at their meeting in Moscow two days ago.

Right now the Baltic 21 process is focusing on the scenarios and policy changes required. This will be followed by formulation of actions to be proposed for the action programme and concensus building within the sectorial groups. During the spring of 1998 the action programme will be compiled and integrated from sector reports and negotiations carried out to finalize the Agenda 21 document.

The Agenda 21 has a strong link to the EU. The goal of the fifth environmental programme of the EU is sustainable development. The Amsterdam treaty has now included sustainable development as one of the basic objectives of the EU. A majority of countries in the Baltic Sea Region are or intend to become members of the EU. The approximation and implementation of EU legislation will obviously play a very important role for the future and for the implementation of Baltic 21.

Baltic 21 will have a very pronounced effect on future developments within the region. Governments agreeing on Baltic 21 will implement the actions agreed on. One part of that will concern the role of international financing institutions like 
the EBRD and the EIB. So far identification of environmental investment objects like municipal waste water treatment plants and polluting industries have been rather straight forward. But when going into the arena of sustainable development all aspects of financing would have to be included in the the picture. In fact, the non-environmental projects in the portofolios of the banks will most likely be the important ones for sustainable development. They would in the long run have to comply with sustainability requirements. How such criteria for sustainable development will look like and how they might be applied is an important job for Baltic 21 to establish. This will certainly also affect the industrial sector.

Another part will deal with the goal of reaching the carrying capacity of the environment concerning biodíversity, ecosystem productivity and management of natural resources. The carrying capacity can be expressed as critical loads for e.g. acidification and eutrophication. These requirements would then have to be explicitly expressed as requirements on sectors, including the industrial sector of the region. When it comes to one specific area - the use of hazardous subtsances - there has already been a decision taken that within one generation ( 25 years) the discharges, emissions and losses of such hazardous substances will have ceased, bringing concentrations in the environment down to background levels for naturally occuring chemicals and to zero levels for synthetic compounds. This work has already started.

The world will gradually have to change to adjust to what is required by sustainable development. There is a lot of work to be done by all actors and not the least by industry itself. You, at this seminar representing engineers, administrators and scientists, are at the vanguard, seeking new and effective solutions to environmental and sustainability problems. I invite all of you to participate in this process, to make your contribution to the Agenda 21 for the Baltic Sea Region. Start by visiting our homepage mentioned earlier to learn more about the work going on and give us your views. I think that those of you who will be at the forefront will also gain the largest rewards. 